\section{Calcium-induced alteration of mitochondrial morphology and mitochondrial-endoplasmic reticulum contacts in rat brown adipocytes}

\author{
I. Golic, ${ }^{1}$ K. Velickovic, ${ }^{1}$ M. Markelic, ${ }^{1}$ \\ A. Stancic, ${ }^{2}$ A. Jankovic, ${ }^{2}$ M. Vucetic, ${ }^{2}$ \\ V. Otasevic, ${ }^{2}$ B. Buzadzic, ${ }^{2}$ B. Korac, ${ }^{2}$ \\ A. Korac ${ }^{1}$
}

${ }^{1}$ Center for Electron Microscopy, Faculty

of Biology, University of Belgrade

${ }^{2}$ Institute for Biological Research "Sinisa

Stankovic", University of Belgrade, Serbia

\section{Abstract}

Mitochondria are key organelles maintaining cellular bioenergetics and integrity, and their regulation of $\left[\mathrm{Ca}^{2+}\right]_{i}$ homeostasis has been investigated in many cell types. We investigated the short-term Ca-SANDOZ ${ }^{\circledR}$ treatment on brown adipocyte mitochondria, using imaging and molecular biology techniques. Two-monthold male Wistar rats were divided into two groups: Ca-SANDOZ ${ }^{\circledR}$ drinking or tap water (control) drinking for three days. Alizarin Red S staining showed increased $\mathrm{Ca}^{2+}$ level in the brown adipocytes of treated rats, and potassium pyroantimonate staining localized electrondense regions in the cytoplasm, mitochondria and around lipid droplets. Ca-SANDOZ ${ }^{\circledR}$ decreased mitochondrial number, but increased their size and mitochondrial cristae volume. Transmission electron microscopy revealed numerous enlarged and fusioned-like mitochondria in the Ca-SANDOZ ${ }^{\circledR}$ treated group compared to the control, and megamitochondria in some brown adipocytes. The $\mathrm{Ca}^{2+}$ diet affected mitochondrial fusion as mitofusin 1 (MFN1) and mitofusin 2 (MFN2) were increased, and mitochondrial fission as dynamin related protein 1 (DRP1) was decreased. Confocal microscopy showed a higher colocalization rate between functional mitochondria and endoplasmic reticulum (ER). The level of uncoupling protein-1 (UCP1) was elevated, which was confirmed by immunohistochemistry and Western blot analysis. These results suggest that Ca-SAND0Z ${ }^{\circledR}$ stimulates mitochondrial fusion, increases mitochondrial-ER contacts and the thermogenic capacity of brown adipocytes.

\section{Introduction}

Brown adipose tissue (BAT) has the unique feature of non-shivering heat production, an essential physiological function which maintains body temperature and dissipates excess energy to control obesity. ${ }^{1-3}$ BAT is mainly found in small rodents, but is also found in human newborns and adults. ${ }^{4}$ Exposure to cold stimulates the proliferation and differentiation of brown adipocytes via adrenergic receptors, and this physiological response involves mitochondrial biogenesis and activation of genes encoding several mitochondrial proteins, including uncoupling protein-1 (UCP1)..$^{5,6}$ UCP1 utilizes proton-motive force for heat production instead of ATP production. ${ }^{7}$

Adrenergic stimulation also increases cytosolic concentrations of $\mathrm{Ca}^{2+} .{ }^{8,9}$ Uptake of $\mathrm{Ca}^{2+}$ by brown adipocytes is controlled by the cooperation of $\alpha_{1}$ and $\beta$ receptors stimulation, as $\alpha_{1}$-adrenergic stimulation leads to intracellular $\mathrm{Ca}^{2+}$ mobilization, ${ }^{10}$ and $\beta$-stimulation leads to inhibition of $\mathrm{Ca}^{2+}$ uptake into the mitochondria. ${ }^{11}$ Following noradrenaline treatment, cultured brown adipocytes exhibited an increase in cytosolic $\mathrm{Ca}^{2+}$ levels ${ }^{12}$ as a result of a flux of both intracellular and extracellular $\mathrm{Ca}^{2+}$ sources. ${ }^{13}$ Furthermore, in experiments on cold-acclimated brown adipocytes, Nakagaki et al. ${ }^{14}$ suggested that noradrenaline and forskolin evoked an elevation in cytosolic $\mathrm{Ca}^{2+}$ level followed by mitochondrial $\mathrm{Ca}^{2+}$ level, and that $\mathrm{Ca}^{2+}$ accumulation in mitochondria depends on the $\mathrm{H}^{+}$gradient produced by electron transport in the respiratory chain. This is in line with earlier studies which indicated that mitochondria can accumulate a large amount of $\mathrm{Ca}^{2+}$ in dependence of mitochondrial energy metabolism. . $^{15,16}$ Mitochondria are physically linked to the endoplasmic reticulum (ER) in many cell types, forming a structure known as the mitochondria-associated ER membrane (MAM).$^{17}$ A recent study revealed that MAM enables mitochondria and ER to exchange calcium and lipids and that ER-mitochondria contacts are involved in regulating mitochondrial energy metabolism. ${ }^{18}$

Mitochondria are dynamic organelles constantly undergoing fission and fusion. During fusion, mitochondria form a mitochondrial network or reticulum, and mitofusins [mitofusin 1 (MFN1) and mitofusin 2 (MFN2)] are the proteins required for fusion of the outer mitochondrial membrane, ${ }^{19,20}$ and optic atrophy 1 protein (OPA1) is required for inner membrane fusion..$^{21}$ Under normal conditions, fusion of the outer membrane is coordinated with fusion of the inner membrane, however, some reports have shown that the fusion machinery of the outer membrane can operate in the absence of inner membrane fusion. ${ }^{22,23}$ The master regulator of mitochondrial fission is dynamin-related protein 1 (DRP1). Cells lacking DRP1 show highly interconnected mitochondrial reticulum formed by fusion in
Correspondence: Prof. Aleksandra Korac, University of Belgrade, Faculty of Biology, Center for Electron Microscopy, Studentski trg 16, 11000 Belgrade, Serbia.

Tel. +381.11.2187266 - Fax: +381.11.2638500.

E-mail: aleksandra.korac@bio.bg.ac.rs

Key words: Brown adipocyte, mitochondrial dynamics, calcium, endoplasmic reticulum.

Contributions: all authors contributed equally and approve the final version.

Conflict of interests: the authors declare no conflict of interest.

Acknowledgments: the authors are grateful to Anita Lazarevic and Maja Bogdanovic for skilled technical assistance. This work is supported by grants from Serbian Ministry of Education, Science and Technological Development (\#173055 and \#173054).

Received for publication: 28 January 2014 . Accepted for publication: 18 July 2014.

This work is licensed under a Creative Commons Attribution NonCommercial 3.0 License (CC BYNC 3.0).

\section{(C) Copyright et al., 2014}

Licensee PAGEPress, Italy

European Journal of Histochemistry 2014; $58: 2377$ doi:10.4081/ejh.2014.2377

the absence of fission activity. ${ }^{24}$

De Meis et al. ${ }^{25}$ performed in vitro experiments with brown adipocytes and showed that mitochondria fusion and influx of calcium into these organelles activate thermogenesis. In this study, we examined the in vivo effect of short-term calcium treatment on mitochondrial dynamics in brown adipocytes, and investigated how $\mathrm{Ca}^{2+}$ affects: i) the balance of mitochondrial fusion and fission; ii) mitochondrial-ER contacts; and iii) the thermogenic capacity of brown adipocytes.

\section{Materials and Methods}

\section{Experimental design}

This study was approved by the Ethics Committee for the Treatment of Experimental Animals (Faculty of Biology, University of Belgrade, Serbia). Two-month-old male Wistar rats (160-240 g) were fed standard pelleted food ad libitum. They were divided into two groups each consisting of six animals - CaSAND0Z $^{\circledR} \quad$ (Novartis, Basel, Switzerland) drinking (480 mg/L Ca ${ }^{2+}$ ) and tap water (control) drinking for three days. Animals were sacrificed using a decapitator (Harvard 
Apparatus, Holliston, MA, USA). The interscapular portion of BAT was dissected out and weighed. One portion of BAT was fixed in 2.5\% glutaraldehyde (v/v) in 0.1 M Sørensen phosphate buffer ( $\mathrm{PB}, \mathrm{pH} 7.2)$. This portion was postfixed in $2 \%$ osmium tetroxide in the same buffer, then routinely dehydrated using increasing concentrations of ethanol and embedded in Araldite (Fluka, Seeize, Germany). One half of another portion of BAT was immediately frozen for protein analyses and other half was cut using a tissue chopper for confocal microscopy analyses.

\section{Transmission electron microscopy}

Ultra-thin sections were obtained using a Leica UC6 ultramicrotome (Leica Microsystems, Wetzlar, Germany), mounted on copper grids and contrasted in uranyl acetate and lead citrate using Leica EM STAIN (Leica Microsystems). Sections were examined on a Philips CM12 transmission electron microscope (Philips/FEI, Eindhoven, The Netherlands) equipped with the digital camera SIS MegaView III (Olympus Soft Imaging Solutions, Münster, Germany). The obtained electron micrographs were used for ultrastructure analysis (mitochondrial morphology) and stereology. The number of mitochondria was obtained by counting the total number of mitochondria per $100 \mu^{2}$ of cell surface. For this analysis, we used 50 randomly selected micrographs per group. Mitochondrial mean diameter was calculated as the average diameter per mitochondrion, 200 mitochondria per group were randomly selected. Mitochondrial volume density was calculated using a derivation of the Deless equation: $V_{v}=P_{m} / P_{\text {total }}$, where $P_{m} / P_{\text {total }}$ is the point fraction or the total points hitting the mitochondria divided by the total points hitting the adipocyte. ${ }^{26}$ Mitochondrial cristae volume density was calculated using a previously described equation with minor modifications, where $\mathrm{P}_{\mathrm{c}} / \mathrm{P}_{\mathrm{mt}}$ is the point fraction or the total points hitting the cristae divided by the total points hitting the mitochondria. All these measurements and analyses were performed using iTEM software (Olympus Soft Imaging Solutions).

\section{Stereological analyses of brown adipocytes and lipid droplets}

Semi-thin sections $(2 \mu \mathrm{m})$ were mounted on glass slides, and stained with $0.1 \%$ toluidine blue in $1 \%$ sodium borate buffer. Stereological values were obtained using the equation: $V_{v}=P_{x} / P_{\text {total }}$, where $P_{x} / P_{\text {total }}$ is the point fraction or the total points hitting the brown adipocytes or lipid droplets, respectively, divided by the total points hitting BAT. All these analyses were performed on a Leica DMLB microscope (Leica Microsystems) using a Weibel 2 graticule. ${ }^{26}$

\section{Immunohistochemistry}

After removal of Araldite with 1\% sodium hydroxide in absolute ethanol $\left(30 \mathrm{~min}, 37^{\circ} \mathrm{C}\right)$, semi-thin BAT sections $(2 \mu \mathrm{m})$, were rehydrated with decreasing concentrations of ethanol, subsequently incubated in citrate buffer for 3 min at $600 \mathrm{~W}$ to retrieve antigens and washed in phosphate buffered saline (PBS, pH 7.4). After blocking endogenous peroxidase by incubating with $3 \%$ hydrogen peroxide in methanol and three sequential washings in PBS, the sections were incubated with rabbit polyclonal UCP-1 antibody (Abcam, Cambridge, UK) overnight at $4^{\circ} \mathrm{C}$. Immunodetection was performed using the Dako LSAB Universal Kit (Dako Scientific, Glostrup, Denmark). The sections which were washed three times were incubated with $0.012 \%$ hydrogen peroxide and 0.05\% diaminobenzidine (Sigma-Aldrich, Seeize, Germany) in PBS for $10 \mathrm{~min}$ in the dark. Finally, after rinsing in distilled water, the sections were counterstained with hematoxylin, mounted and examined with a Leica DMLB microscope (Leica Microsystems).

\section{Confocal imaging and colocalization}

Immediately after dissection, BAT was minced into small tissue fragments using a Mcllwain tissue chopper (Mickle Laboratory Engineering, Guildford, UK), then incubated in PBS with $100 \mathrm{nM}$ MitoTracker Orange CMTMRos (Invitrogen, Darmstadt, Germany) and $1 \mu \mathrm{M}$ ER-Tracker Green (Invitrogen) for 45 min at $37^{\circ} \mathrm{C}$. After incubation, the samples were washed twice in PBS, and fixed with $4 \%$ paraformaldehyde in PBS. After a final washing in PBS, the samples were mounted with Mowiol and analyzed by a Leica TCS SP5 II confocal microscope (Leica Microsystems). The colocalization rate was determined using LAS AF software (Leica Microsystems) under the following parameters and formulas: threshold $30 \%$, background $20 \%$, colocalization rate [\%] = colocalization area/area foreground, and area foreground = area image - area background.

Relative fluorescence intensity of MitoTracker Orange CMTMRos was determined at several regions of interest (ROI) using LAS AF software. ROI consisting of randomly localized intracellular regions were drawn by free hand and applied to images.

\section{Alizarin Red S staining}

After incubation in $1 \%$ sodium hydroxide in absolute ethanol for $30 \mathrm{~min}$ at $37^{\circ} \mathrm{C}$ and rehydration with decreasing concentrations of ethanol, semi-thin BAT sections were incubated in Alizarin Red $\mathrm{S}$ solution for 2 min, followed by acetone, acetone/xylene and xylene dehydration. Sections were mounted, and analyzed using a Leica DMLB microscope (Leica Microsystems, Germany). Alizarin Red S shows the presence and localization of calcium by forming insoluble chelates with calcium ions from their deposits which gives an orange to red reaction.

\section{Potassium pyroantimonate staining}

BAT was fixed in $2.5 \%$ glutaraldehyde $(\mathrm{v} / \mathrm{v})$ in $0.1 \mathrm{M}$ phosphate buffer ( $\mathrm{pH} 7.2)$ containing $2 \%$ potassium pyroantimonate (w/v). Samples were washed, postfixed in $2 \%$ osmium tetroxide in phosphate-buffered antimonate. After rinsing with the same buffer without antimonate, the samples were routinely dehydrated using ethanol and embedded in Araldite. For the control samples, buffer without potassium pyroantimonate was used in the fixation and postfixation steps. Antimonate forms a precipitate with calcium ions which demonstrates the in situ localization of calcium.

\section{SDS-PAGE and Western blotting}

Protein content was estimated by the method of Lowry et al. ${ }^{27}$ using bovine serum albumin as a reference. Immunoblot analyses were performed on isolated BAT as described previously. ${ }^{28}$ Primary antibodies against MFN1 (5 $\mu \mathrm{g} / \mathrm{mL})$, MFN2 (5 $\mu \mathrm{g} / \mathrm{mL})$, DRP1 (1:1000), voltage-dependent anion-selective channel (VDAC) (1:1000), calnexin $(1 \mu \mathrm{g} / \mathrm{ml})$ and UCP1 (1:1000) were purchased from Abcam (Cambridge, UK). Quantitative analyses of immunoreactive bands were carried out using ImageJ software (NIH, USA). The volume represents the sum of all pixel intensities within a band, and 1 pixel $=0.007744 \mathrm{~mm}^{2}$. The density of each protein signal was normalized to that of the internal control, $\beta$-actin (Abcam, UK). The mean values obtained from the control group were taken as $100 \%$ and those from the $\mathrm{Ca}-\mathrm{SANDOZ}^{\circledR}$ group were expressed as percentages with respect to the control.

\section{Statistics}

The Student's $t$-test was performed for analyses of the data using GraphPad Prism for Mac OS X. Statistical significance was set at $\mathrm{P}<0.05$.

\section{Results and Discussion \\ Increased $\mathrm{Ca}^{2+}$ level and its local- ization in brown adipocytes}

Alizarin Red S histochemical staining revealed a higher level of $\mathrm{Ca}^{2+}$ salts in the treated group, visualized as groups of brown adipocytes with higher intensities of red color (Figure 1 A,B). This is known as the harlequin effect, ${ }^{29}$ due to the different functional capacity of brown adipocytes. At the ultrastructure level, potassium pyroantimonate staining localized $\mathrm{Ca}^{2+}$ as electron-dense regions in the 
cytoplasm, mitochondria and around lipid droplets, with higher concentrations in the CaSANDOZ ${ }^{\circledR}$ treated group compared to the control group (Figure $1 \mathrm{C}, \mathrm{D}$ ). The negative control revealed no pyroantimonate precipitates in brown adipocytes (Figure 1E). $\mathrm{Ca}^{2+}$ uptake from the extracellular medium is necessary to maintain elevated cytosolic $\mathrm{Ca}^{2+}$ concentration as a result of hormone response in many cell types. ${ }^{30}$ Depletion of $\mathrm{Ca}^{2+}$ from intracellular stores, such as ER or mitochondria, causes $\mathrm{Ca}^{2+}$ intake via $\mathrm{Ca}^{2+}$-permeable channels in the plasma membrane. ${ }^{31}$ This is in accordance with our results which clearly shows that even short Ca-SAND0Z ${ }^{\circledR}$ intake induce $\mathrm{Ca}^{2+}$ uptake by rat brown adipocytes and their accumulation in cytoplasm and mitochondria. Brown adipocytes exhibited an increase in intracellular $\mathrm{Ca}^{2+}$ in vitro caused by a flux of both intracellular and extracellular $\mathrm{Ca}^{2+}$ after noradrenaline application via the $\alpha$-adrenergic and/or $\beta$ adrenergic pathway. ${ }^{12,13}$ The mitochondrial uncoupling via UCP-1 by $\beta_{3}$-adrenergic activation causes $\mathrm{Ca}^{2+}$ release from mitochondria and subsequently from the ER via inositol 1,4,5-triphosphate ( $\operatorname{Ins}_{3}$ ) receptors, and further activates plasmalemmal $\mathrm{Ca}^{2+}$ entries into rodent brown adipocytes. ${ }^{32}$ Hence, it could be suggested that Ca-SANDOZ ${ }^{\circledR}$ supplementation mimics cold-exposure and alters mitochondrial morphology and thermogenic capacity of rat brown adipocyte.

\section{Ca-SANDOZ ${ }^{\circledR}$ alters mitochondrial morphology and dynamics}

Mitochondria of brown adipocytes show many variations in internal structure. TEM showed that mitochondria from the control group were mainly round with few lamellar cristae (Figure 2A). In contrast, the treated group had larger, fusioned-like mitochondria with numerous well-developed lamellar cristae (Figure 2B) and may be relevant to subsequent swelling of mitochondria. ${ }^{3}$ Megamitochondria were found in the Ca-SANDOZ ${ }^{\circledR}$ treated group in some brown adipocytes (harlequin effect) (Figure 3), which has been described in the literature for various pathological disorders or perturbed physiological conditions. ${ }^{33,34}$ Megamitochondria are also associated with various diseases, where liver and skeletal muscles are the major tissues in which these structures have been detected. They are frequently associated with alcoholic liver disease, hepatic steatosis and other diseases, ${ }^{35-37}$ where pathological changes, e.g. paracrystalline inclusions are detected.$^{38}$ In our experiment, no megamitochondria were observed in the control group. There are several possible mechanisms of megamitochondria formation. Hypertrophy of an individual mitochondrion has been detected in the liver of experimental animals fed a high protein diet, due to increased nitrogen metabolism. ${ }^{39}$ Chloramphenicol induces the formation of hepatic megamitochondria, probably due to protein synthesis inhibition in mitochondria ${ }^{40}$ Free radicals initiate the formation of megamitochondria when they exceed the enzymatic and non-enzymatic

defense system against reactive oxygen species (ROS). The rate of oxygen consumption and phosphorylation capacity of megamitochondria is often lowered ${ }^{41-43}$ or remained normal. ${ }^{44}$ Since TEM did not show any pathological changes in mitochondria and brown
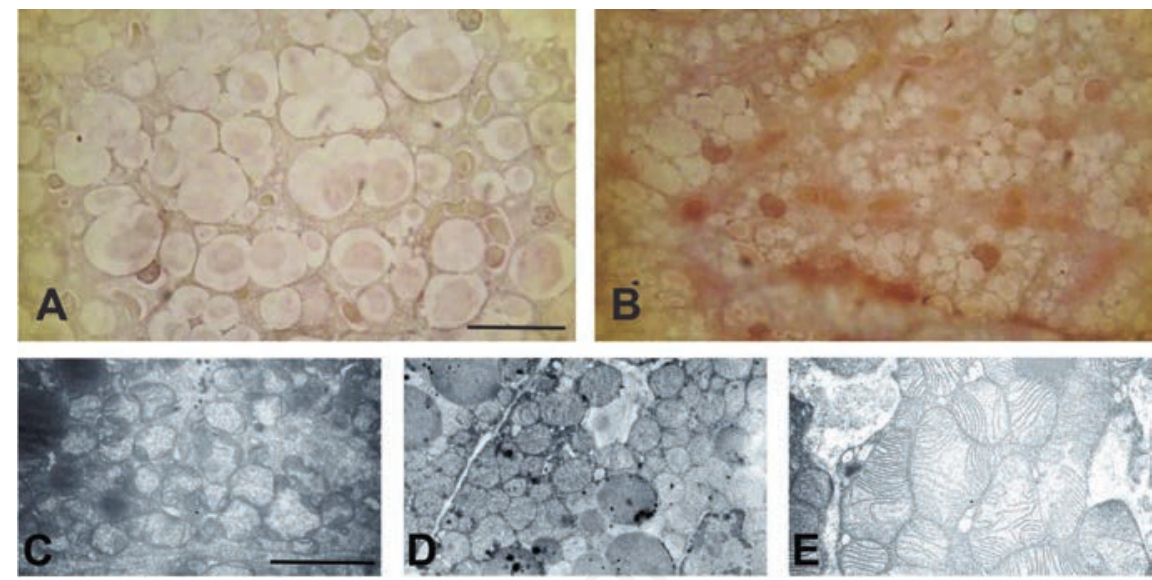

Figure 1. Alizarin Red $S$ and potassium pyroantimonate staining. Alizarin Red $S$ staining showed a higher level of calcium salts in the Ca-SANDOZ ${ }^{\circledR}$ treated group (B) compared to the control group (A). Potassium pyroantimonate staining localized $\mathrm{Ca}^{2+}$ electrondense regions in the control (C) and Ca-SANDOZ ${ }^{\circledR}$ group (D). Negative control for pyroantimonate staining (E). Scale bars: A,B, $20 \mu \mathrm{m}$; C-E, $2 \mu \mathrm{m}$.
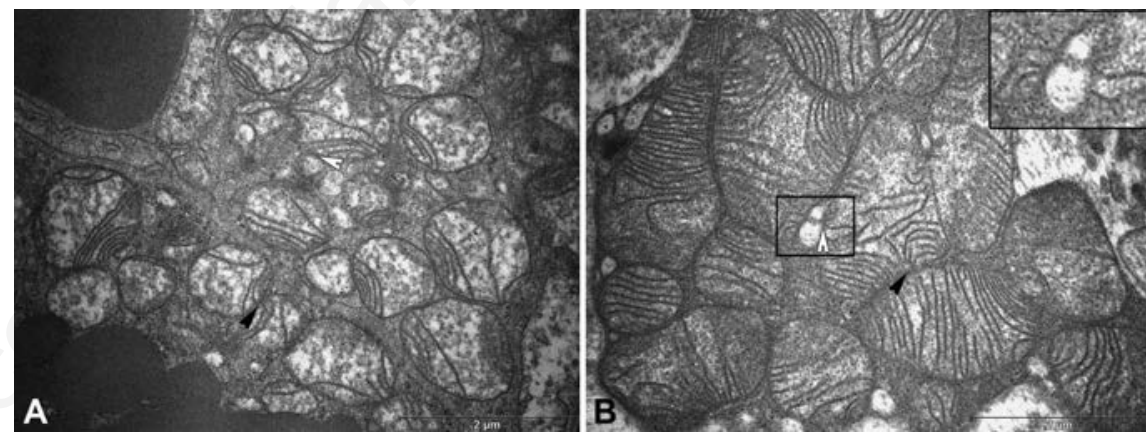

Figure 2. Electron microscopy of brown adipocyte mitochondria. A) Round mitochondria with few lamellar cristae showing intimate contact between mitochondria (black arrowheads) and between mitochondria and endoplasmic reticulum (ER; white arrowheads) in the control group. B) Larger mitochondria with numerous cristae in the Ca-SANDOZ ${ }^{\circledR}$ group. Inset: Detail of intimate contact between mitochondria and ER. Scale bars: $2 \mu \mathrm{m}$.

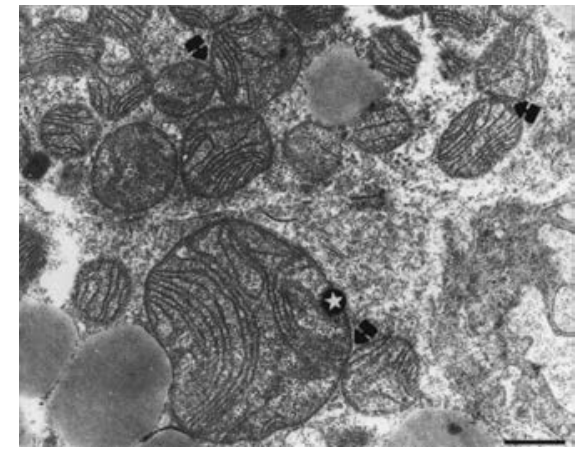

Figure 3. Megamitochondria. A brown adipocyte from the Ca-SANDOZ ${ }^{\circledR}$ treated group shows a mitochondrial cluster with megamitochondria (star) and numerous intermitochondrial contacts (arrows). Scale bar: $1 \mu \mathrm{m}$. 
adipocytes, it cannot be determined what caused the appearance of these specific mitochondrial structures due to controversies regarding the formation of megamitochondria. Further investigations are needed to clarify the mechanism of a high $\mathrm{Ca}^{2+}$ diet on megamitochondria formation in brown adipocytes. Intimate contact between mitochondria and the ER was observed (Figure 2).

Ca-SANDOZ $^{\circledR}$ treatment caused a significant decrease in mitochondria number per 100 $\mu \mathrm{m}^{2}$ and shifted the mean mitochondrial diameter to a higher value (Figure $4 \mathrm{~A}, \mathrm{~B}$ ), which is consistent with the observed fusion process. Stereological analyses also showed an increase in mitochondrial cristae volume (Figure 4C). These results are in line with reports on the increasing number and density of cristae in brown adipocytes after exposure to cold. ${ }^{45,46}$ Increased cristae fraction, i.e. remodeling may be in response to mitochondrial fusion to avoid an excessive membrane area and maintain the density of the matrix. ${ }^{47}$ During mitochondrial remodeling, cells use several strategies to increase ATP production including an increase in mitochondrial size, an increase in the total number of mitochondria per cell, and an increase in the volume of mitochondria per cell and/or surface area of mitochondrial cristae membranes. A wide variety of cells use these strategies during transitions between the normal physiological milieu, pharmacological or toxicological treatments, and pathological or disease states. ${ }^{48,49}$ In apoptosis, mitochondrial remodeling is important for mobilization of cytochrome $c$ stores in cristae. $^{50}$ The volume density of mitochondria was not changed (Figure 4D), which was confirmed by the unchanged level of relative protein expression of VDAC, a mitochondrial outer membrane marker (Figure 4E). As expected, the levels of calnexin, an ER membrane marker, were not changed (Figure 4F). These results indicate that short-term in vivo $\mathrm{Ca}^{2+}$ treatment does not stimulate mitochondrial and ER biogenesis, but induces their rearrangement and numerous contact sites.

Mitochondrial fusion players, MFN1 and MFN2, were significantly increased in the treated group (Figure $5 \mathrm{~A}, \mathrm{~B}$ ), suggesting mitochondrial fusion..$^{19}$ On the other hand, DRP1, a mitochondrial fission player, was decreased (Figure 5C). Mitochondria are dynamic organelles constantly undergoing fission and fusion, thus the ER provides a constant and well-regulated supply of phospholipids for cristae and membrane integrity. ${ }^{51-53}$ More MFN2 proteins were available for establishing mitochondria-ER contacts, which was elegantly demonstrated using mouse embryonic fibroblasts. ${ }^{54}$ To ensure optimal bioenergetics and efficient mitochondrial respiration, ERmitochondria contact is necessary for a con- stant $\mathrm{Ca}^{2+}$ supply via the $\mathrm{InsP}_{3}$ receptor. This $\mathrm{Ca}^{2+}$ supply provides reducing equivalents to support oxidative phosphorylation. ${ }^{55}$ In addition, $\mathrm{Ca}^{2+}$ can activate enzymes of the tricarboxylic acid cycle (TCA) including pyruvate dehydrogenase, $\alpha$-ketoglutarate and isocitrate dehydrogenase ${ }^{17,56}$ to increase flux throughout the TCA cycle. Furthermore, fusion of mitochondria may be protective against damage to mitochondrial $\mathrm{DNA}^{57}$ due to elevated production of ROS as a result of increased respiratory activity ${ }^{58,59}$ and fatty acid oxidation. ${ }^{60,61}$

Confocal microscopy revealed a higher colocalization rate between active mitochondria and $\mathrm{ER}$ in the $\mathrm{Ca}^{-S A N D O Z}{ }^{\circledR}$ treated group (Figure 6B), indicating increased mitochondria-ER contacts probably due to higher demands for $\mathrm{Ca}^{2+}$ inter-organelle crosstalk, as previously described. ${ }^{62,63}$ Higher mitochondrial membrane potential is observed in Ca-SAN$\mathrm{DOZ}^{\circledR}$ treated group (Figure 6C), indicating elevated uptake of $\mathrm{Ca}^{2+}$ ions into mitochondria, which is in line with some studies revealing that $\mathrm{Ca}^{2+}$ uptake is driven by the mitochondrial membrane potential. ${ }^{64-66}$ Our future study will be directed at this specific point to determine to what extent this communication is important for activation of brown adipocytes.

\section{Ca-SANDOZ ${ }^{\circledR}$ increases thermogenic capacity of BAT}

Immunohistochemical analysis showed higher expression of UCP1 protein in the CaSANDOZ $^{\circledR}$ treated group (Figure 7B), which was confirmed by a significant increase in the level of relative UCP1 protein expression
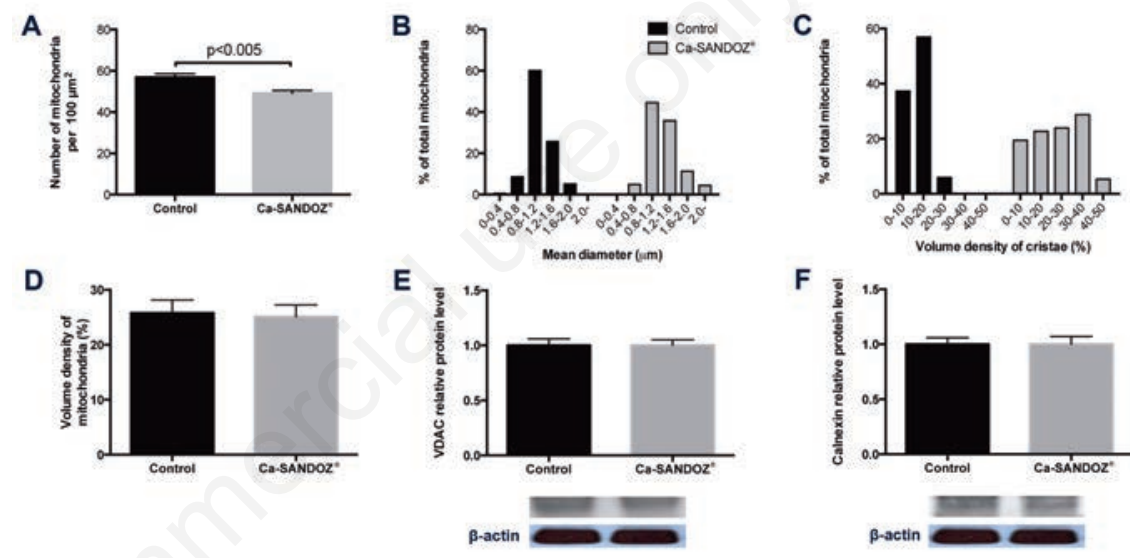

$\mathbf{F}$

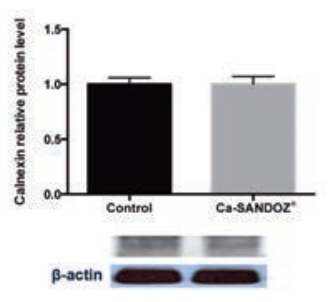

Figure 4. Mitochondrial stereology and analyses. Calnexin (endoplasmic reticulum membrane marker) protein level. A) Mitochondrial number per unit surface was decreased in adipocytes of the Ca-SANDOZ ${ }^{\circledR}$ treatment group. B) Distribution histogram of mitochondrial diameters demonstrating a shift to higher values after Ca-SANDOZ ${ }^{\circledR}$ treatment. C) Distribution histogram of cristae volume density; treatment stimulated cristae formation. D) Volume density of mitochondria was unchanged. E) The relative protein expression level of VDAC, a mitochondrial outer membrane marker, was unchanged. F) The relative protein expression level of calnexin, an ER membrane marker, was unchanged. Protein content is expressed relative to the control, which was standardized to $100 \%$, as the mean \pm SEM and represents three similar independent experiments with triplicate observations in each experiment. A representative blot is shown. Volume is the sum of all pixel intensities within a band $\left(1\right.$ pixel $\left.=0.007744 \mathbf{m m}^{2}\right)$.
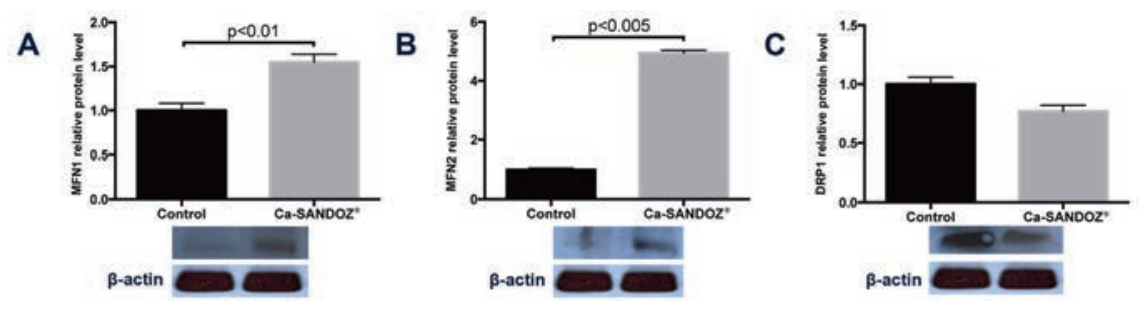

Figure 5. Markers of mitochondrial dynamics. A) Increased MFN1 relative protein expression compared to the control. B) Increased MFN2 relative protein expression compared to the control. C) Reduced DRP1 protein expression in BAT of treated rats. Protein content is expressed relative to the control, which was standardized to $100 \%$, as the mean \pm SEM and represents three similar independent experiments with triplicate observations in each experiment. A representative blot is shown. Volume is the sum of all pixel intensities within a band $\left(1\right.$ pixel $\left.=0.007744 \mathbf{m m}^{2}\right)$. 

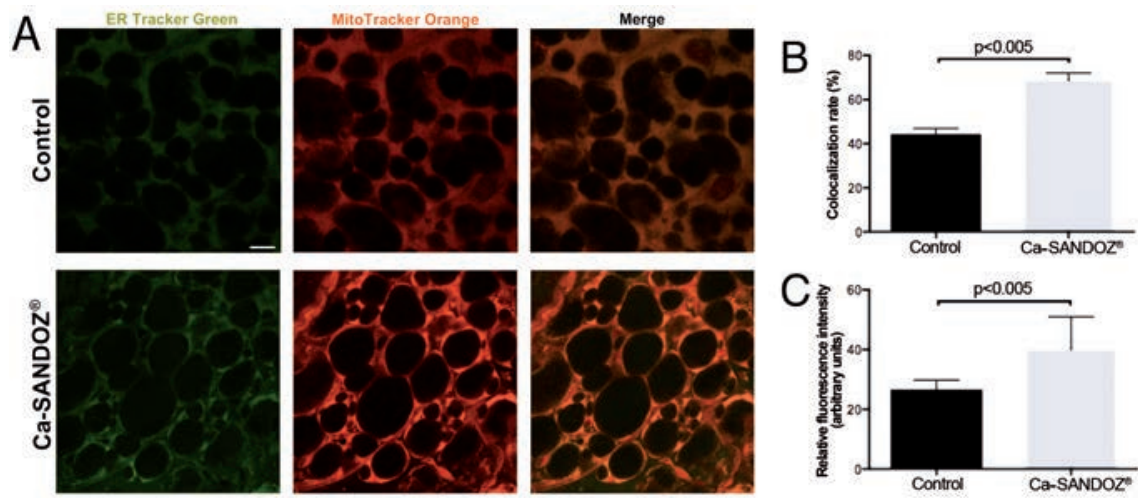

Figure 6. Fluorescence labeling of mitochondria using MitoTracker Orange CMTMRos and ER using ER-Tracker Green. A) Confocal images of mitochondria and ER from the control group and Ca-SANDOZ ${ }^{\circledR}$ treated group. B) Increased colocalization rate between mitochondria and $\mathrm{ER}$ in the $\mathrm{Ca}-\mathrm{SANDOZ}{ }^{\circledR}$ treated group compared to the control group. C) Increased relative fluorescence intensity of MitoTracker Orange CMTMRos in the CaSANDOZ ${ }^{\circledR}$ treated group compared to control. Scale bars: $5 \mu \mathrm{m}$.

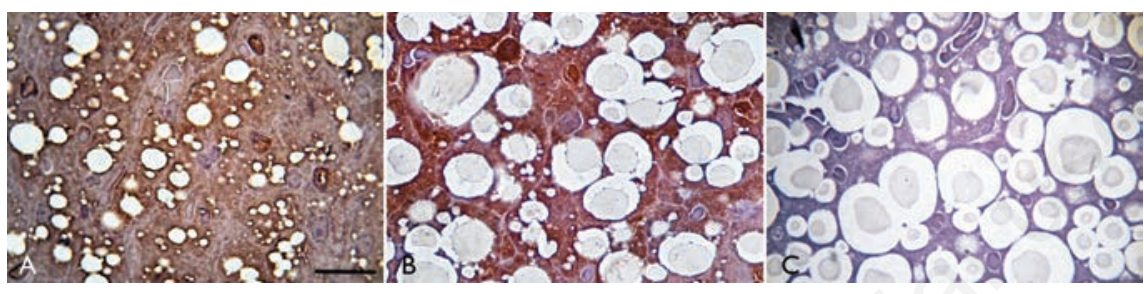

Figure 7. UCP1 immunohistochemistry. Immunohistochemical analysis showed higher expression of UCP1 protein in the Ca-SANDOZ ${ }^{\circledR}$ treated group. A) Control group. B) Ca-SANDOZ ${ }^{\circledR}$ group. C) Negative control. Scale bars: $20 \mu \mathrm{m}$.

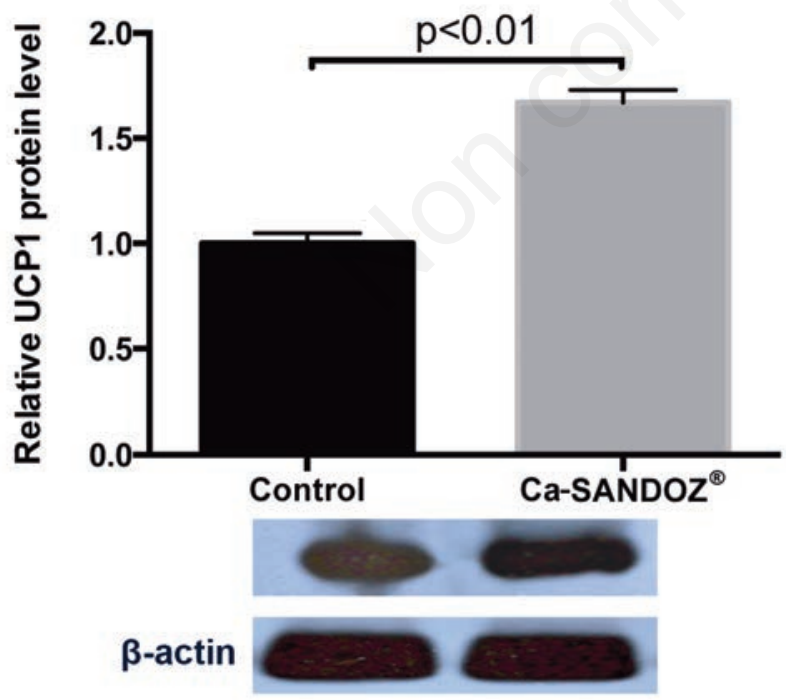

Figure 8. UCP1 protein level. Increased level of UCP1 protein in the Ca-SANDOZ ${ }^{\circledR}$ group compared to the control group. Protein content is expressed relative to the control, which was standardized to $100 \%$, as the mean \pm SEM and represents three similar independent experiments with triplicate observations in each experiment. A representative blot is shown. Volume is the sum of all pixel intensities within a band $\left(1\right.$ pixel $\left.=0.007744 \mathrm{~mm}^{2}\right)$.
(Figure 8). Increased UCP1 expression leads to increased thermogenesis., ${ }^{5,67,68}$ More cristae, where oxidative phosphorylation (OXPHOS) machinery is located, ${ }^{69}$ are developed as a result of enhanced activity of the respiratory chain compensating proton leaks via the UCP1 uncoupling mechanism. However, the precise details of this process are still unclear. ${ }^{70-72}$

In this experiment, we also observed body mass loss in the Ca-SANDOZ ${ }^{\circledR}$ treated group $(-18.46 \pm 0.56 \%)$, compared to control animals. Stereological analyses of brown adipocytes and lipid droplets (Table 1) revealed that high calcium diet triggers lipolysis. This observation is in line with the process of adaptive thermogenesis, where catecholamine-stimulated lipolysis provides fatty acids for heat production in response to cold or overfeeding. ${ }^{73}$ As a result of short-term thermogenesis, BAT may shrink due to increased lipolysis. Possible mechanisms of calcium effect on body weight were investigated using animal models and human volunteers. ${ }^{74}$ Also, Marotte et al. reported that low calcium intake may increase body weight, especially in rats predisposed to obesity. ${ }^{75}$ In humans, numerous studies have shown that high calcium intake may have an impact on weight loss. ${ }^{76-80}$ Several mechanisms of high calcium diet are proposed: i) inhibition of lipogenesis and stimulation of lipolysis via suppression of circulating $1 \alpha, 25$-dihydroxycholecalciferol; ${ }^{81-85}$ and ii) increase in fetal excretion of fat via the formation of insoluble calcium fatty acid soaps. ${ }^{86,87}$ From our results, it seems that high calcium uptake has a beneficial effect on weight control or loss, as a result of increased thermogenic capacity, at least in rats. Here, we propose a third mechanism high calcium diet affects body weight due to increasing thermogenic capacity of brown adipocytes and, consequently, increased lipolysis for elevated energy expenditure.

In conclusion, short-term in vivo treatment with $\mathrm{Ca}$-SANDOZ ${ }^{\circledR}$ stimulates mitochondrial fusion, increases mitochondrial-ER contacts and thermogenic capacity in brown adipocytes. Further studies addressing the molecular mechanism of $\mathrm{Ca}^{2+}$ action on mitochondria are needed to understand their role in the mitochondrial bioenergetics of brown adipocytes during thermogenesis.

Table 1. Effect of Ca-SANDOZ ${ }^{\circledR}$ treatment on brown adipocytes.

\begin{tabular}{lcc} 
& Control & Ca-SANDOZ ${ }^{\odot}$ \\
$\begin{array}{l}\text { Relative BAT mass } \\
\text { (mg/100 g of animal weight) }\end{array}$ & $82.6 \pm 5.39$ & $77.03 \pm 2.36$ \\
$\mathrm{~V}_{\mathrm{v}}$ of brown adipocytes (\%) & $83.51 \pm 0.69$ & $57.89 \pm 3.00^{*}$ \\
\hline $\mathrm{V}_{\mathrm{v}}$ of lipid droplets (\%) & $43.63 \pm 2.14$ & $27.67 \pm 0.87^{*}$ \\
\hline
\end{tabular}

BAT, brown adipose tissue. Data represents the mean \pm SEM. ${ }^{*} \mathrm{P}<0.005$ 


\section{References}

1. Cannon B, Nedergaard J. Brown adipose tissue: function and physiological significance. Physiol Rev 2004;84:277-359.

2. Himms-Hagen J. Brown adipose tissue metabolism and thermogenesis. Annu Rev Nutr 1985;5:69-94.

3. Nicholls DG, Locke RM. Thermogenic mechanisms in brown fat. Physiol Rev 1984;64:1-64.

4. Nedergaard J, Bengtsson T, Cannon B. Unexpected evidence for active brown adipose tissue in adult humans. Am J Physiol Endocrinol Metab 2007;293:E444-52.

5. Bouillaud F, Ricquier D, Mory G, Thibault J. Increased level of mRNA for the uncoupling protein in brown adipose tissue of rats during thermogenesis induced by cold exposure or norepinephrine infusion. J Biol Chem 1984;259:11583-6.

6. Klingenspor $\mathrm{M}$, Ivemeyer $\mathrm{M}$, Wiesinger $\mathrm{H}$, Haas K, Heldmaier G, Wiesner RJ. Biogenesis of thermogenic mitochondria in brown adipose tissue of Djungarian hamsters during cold adaptation. Biochem J 1996;316:607-13.

7. Nicholls DG, Rial E. A history of the first uncoupling protein, UCP1. J Bioenerg Biomembr 1999;31:399-406.

8. Leaver EV, Pappone PA. Beta-adrenergic potentiation of endoplasmic reticulum $\mathrm{Ca}(2+)$ release in brown fat cells. Am $\mathrm{J}$ Physiol Cell Physiol 2002;282:C1016-24.

9. Nicholls DG. The physiological regulation of uncoupling proteins. Biochim Biophys Acta 2006;1757:459-66.

10. Connolly E, Nånberg E, Nedergaard J. Na+dependent, alpha-adrenergic mobilization of intracellular (mitochondrial) $\mathrm{Ca} 2+$ in brown adipocytes. Eur J Biochem 1984; 141:187-93.

11. Connolly E, Nedergaard J. Beta-adrenergic modulation of $\mathrm{Ca} 2+$ uptake by isolated brown adipocytes. Possible involvement of mitochondria. J Biol Chem 1988;263: 10574-82.

12. Wilcke M, Nedergaard J. Alpha 1- and betaadrenergic regulation of intracellular $\mathrm{Ca} 2+$ levels in brown adipocytes. Biochem Biophys Res Commun 1989;163:292-300.

13. Lee SC, Nuccitelli R, Pappone PA. Adrenergically activated $\mathrm{Ca} 2+$ increases in brown fat cells: effects of $\mathrm{Ca} 2+, \mathrm{K}+$, and $\mathrm{K}$ channel block. Am J Physiol 1993;264: C217-28.

14. Nakagaki I, Sasaki S, Yahata T, Takasaki H, Hori S. Cytoplasmic and mitochondrial $\mathrm{Ca}$ levels in brown adipocytes. Acta Physiol Scand 2005;183:89-97.

15. Hittelman KJ, Fairhurst AS, Smith RE. Calcium accumulation as a parameter of energy metabolism in mitochondria of brown adipose tissue. Proc Natl Acad Sci USA
1967;58:697-702.

16. Vasington FD, Murphy JV. Ca ion uptake by rat kidney mitochondria and its dependence on respiration and phosphorylation. J Biol Chem 1962;237:2670-7.

17. Hayashi T, Rizzuto R, Hajnoczky G, Su TP. MAM: more than just a housekeeper. Trends Cell Biol 2009;19:81-8.

18. Otera $\mathrm{H}$, Ishihara $\mathrm{N}$, Mihara K. New insights into the function and regulation of mitochondrial fission. Biochim Biophys Acta 2013;1833:1256-68.

19. Chen H, Detmer SA, Ewald AJ, Griffin EE, Fraser SE, Chan DC. Mitofusins Mfnl and Mfn2 coordinately regulate mitochondrial fusion and are essential for embryonic development. J Cell Biol 2003;160:189-200.

20. Santel A, Fuller MT. Control of mitochondrial morphology by a human mitofusin. J Cell Sci 2001;114:867-74.

21. Olichon A, Baricault L, Gas N, Guillou E, Valette A, Belenguer P, et al. Loss of OPA1 perturbates the mitochondrial inner membrane structure and integrity, leading to cytochrome $\mathrm{c}$ release and apoptosis. J Biol Chem 2003;278:7743-6.

22. Malka F, Guillery 0, Cifuentes-Diaz C, Guillou E, Belenguer P, Lombès A, et al. Separate fusion of outer and inner mitochondrial membranes. EMBO Rep 2005;6:853-9.

23. Meeusen S, McCaffery JM, Nunnari J. Mitochondrial fusion intermediates revealed in vitro. Science 2004;305:1747-52.

24. Smirnova E, Shurland DL, Ryazantsev SN, van der Bliek AM. A human dynamin-related protein controls the distribution of mitochondria. J Cell Biol 1998;143:351-8.

25. de Meis L, Ketzer LA, da Costa RM, de Andrade IR, Benchimol M. Fusion of the endoplasmic reticulum and mitochondrial outer membrane in rats brown adipose tissue: activation of thermogenesis by $\mathrm{Ca} 2+$. PLoS One 2010;5:e9439.

26. Weibel ER, Kistler GS, Scherle WF. Practical stereological methods for morphometric cytology. J Cell Biol 1966;30:23-38.

27. Lowry $\mathrm{OH}$, Rosebrough NJ, Farr AL, Randall RJ. Protein measurement with the Folin phenol reagent. J Biol Chem 1951;193:265-75.

28. Korac A, Buzadzic B, Petrovic V, Vasilijevic A, Jankovic A, Micunovic K, et al. The role of nitric oxide in remodeling of capillary network in rat interscapular brown adipose tissue after long-term cold acclimation. Histol Histopathol 2008;23:441-50.

29. Cinti S, Cancello R, Zingaretti MC, Ceresi E, De Matteis R, Giordano A, et al. CL316,243 and cold stress induce heterogeneous expression of UCP1 mRNA and protein in rodent brown adipocytes. J Histochem Cytochem 2002;50:21-31.

30. Pozzan T, Di Virgilio F, Vicentini LM, Meldolesi J. Activation of muscarinic receptors in PC12 cells. Stimulation of $\mathrm{Ca} 2+$ influx and redistribution. Biochem $\mathrm{J}$ 1986;234:547-53.

31. Putney JW. Capacitative calcium entry in the nervous system. Cell Calcium 2003;34: 339-44.

32. Hayato R, Higure Y, Kuba M, Nagai $H$, Yamashita H, Kuba K. $\beta_{3}$-Adrenergic activation of sequential $\mathrm{Ca}(2+)$ release from mitochondria and the endoplasmic reticulum and the subsequent $\mathrm{Ca}(2+)$ entry in rodent brown adipocytes. Cell Calcium 2011;49:400-14.

33. Chedid A, Jao W, Port J. Megamitochondria in hepatic and renal disease. Am J Gastroenterol 1980;73:319-24.

34. Sun CN, Dhalla NS, Olson RE. Formation of gigantic mitochondria in hypoxic isolated perfused rat hearts. Experientia 1969;25: $763-4$.

35. Iseri OA, Gottlieb LS. Alcoholic hyalin and megamitochondria as separate and distinct entities in liver disease associated with alcoholism. Gastroenterology 1971; 60:1027-35.

36. Petersen P. Abnormal mitochondria in hepatocytes in human fatty liver. Acta Pathol Microbiol Scand A 1977;85:413-20.

37. Prieto I, Jiménez F, Aller MA, Nava MP, Vara E, Garcia C, et al. Tumor necrosis factoralpha, interleukin-1beta and nitric oxide: induction of liver megamitochondria in prehepatic portal hypertensive rats. World J Surg 2005;29:903-8.

38. Soares J0, Nunes JF. Intramitochondrial paracrystalline inclusions in human hepatocytes. Am J Clin Pathol 1979;71:479-80.

39. Zaragozá R, Renau-Piqueras J, Portolés M, Hernández-Yago J, Jordá A, Grisolía S. Rats fed prolonged high protein diets show an increase in nitrogen metabolism and liver megamitochondria. Arch Biochem Biophys 1987;258:426-35.

40. Albring M, Radsak K, Thoenes W. Chloramphenicol-induced giant hepatic mitochondria. Naturwissenschaften 1975; 62:43-4.

41. Karbowski M, Kurono C, Wozniak M, Ostrowski M, Teranishi M, Nishizawa Y, et al. Free radical-induced megamitochondria formation and apoptosis. Free Radic Biol Med 1999;26:396-409.

42. Shishido S, Koga H, Harada M, Kumemura H, Hanada S, Taniguchi E, et al. Hydrogen peroxide overproduction in megamitochondria of troglitazone-treated human hepatocytes. Hepatology 2003;37:136-47.

43. Wakabayashi T, Adachi K, Matsuhashi T, Wozniak M, Antosiewicz J, Karbowsky M. Suppression of the formation of megamitochondria by scavengers for free radicals. Mol Aspects Med 1997;18:S51-61.

44. Wakabayashi T, Horiuchi M, Sakaguchi M, Misawa $\mathrm{K}$, Onda $\mathrm{H}$, Iijima $\mathrm{M}$, et al. 
Mechanism of hepatic megamitochondria formation by ammonia derivatives. Correlation between structure of chemicals and their ability to induce the formation of megamitochondria. Eur J Biochem 1984; 143:455-65.

45. Goglia F, Géloën A, Lanni A, Minaire Y, Bukowiecki LJ. Morphometric-stereologic analysis of brown adipocyte differentiation in adult mice. Am J Physiol 1992;262: C1018-23.

46. Petrović V, Korać A, Buzadzić B, Vasilijević A, Janković A, Mićunović K, et al. Nitric oxide regulates mitochondrial re-modelling in interscapular brown adipose tissue: ultrastructural and morphometric-stereologic studies. J Microsc 2008;232:542-8.

47. Gazaryan IG, Brown AM. Intersection between mitochondrial permeability pores and mitochondrial fusion/fission. Neurochem Res 2007;32:917-29.

48. Perkins GA, Ellisman MH, Fox DA. Threedimensional analysis of mouse rod and cone mitochondrial cristae architecture: bioenergetic and functional implications. Mol Vis 2003;9:60-73.

49. Smith RA, Ord MJ. Mitochondrial form and function relationships in vivo: their potential in toxicology and pathology. Int Rev Cytol 1983;83:63-134.

50. Scorrano L, Ashiya M, Buttle K, Weiler S, Oakes SA, Mannella CA, et al. A distinct pathway remodels mitochondrial cristae and mobilizes cytochrome c during apoptosis. Dev Cell 2002;2:55-67.

51. Jungalwala FB, Dawson RM. Phospholipid synthesis and exchange in isolated liver cells. Biochem J 1970;117:481-90.

52. Osman C, Voelker DR, Langer T. Making heads or tails of phospholipids in mitochondria. J Cell Biol 2011;192:7-16.

53. Twig G, Elorza A, Molina AJ, Mohamed H, Wikstrom JD, Walzer G, et al. Fission and selective fusion govern mitochondrial segregation and elimination by autophagy. EMBO J 2008;27:433-46.

54. de Brito OM, Scorrano L. Mitofusin 2 tethers endoplasmic reticulum to mitochondria. Nature 2008;456:605-10.

55. Cárdenas C, Miller RA, Smith I, Bui T, Molgó J, Müller M, et al. Essential regulation of cell bioenergetics by constitutive InsP3 receptor $\mathrm{Ca} 2+$ transfer to mitochondria. Cell 2010;142:270-83.

56. Denton RM, Randle PJ, Bridges BJ, Cooper RH, Kerbey AL, Pask HT, et al. Regulation of mammalian pyruvate dehydrogenase. Mol Cell Biochem 1975;9:27-53.

57. Chen H, Chomyn A, Chan DC. Disruption of fusion results in mitochondrial heterogeneity and dysfunction. J Biol Chem 2005;280: 26185-92.

58. Balaban RS, Nemoto $\mathrm{S}$, Finkel $\mathrm{T}$. Mitochondria, oxidants, and aging. Cell
2005;120:483-95.

59. Li X, Fang P, Mai J, Choi ET, Wang H, Yang XF. Targeting mitochondrial reactive oxygen species as novel therapy for inflammatory diseases and cancers. J Hematol Oncol 2013;6:19.

60. Rosca MG, Vazquez EJ, Chen Q, Kerner J, Kern TS, Hoppel CL. Oxidation of fatty acids is the source of increased mitochondrial reactive oxygen species production in kidney cortical tubules in early diabetes. Diabetes 2012;61:2074-83.

61. Schönfeld P, Wojtczak L. Brown adipose tissue mitochondria oxidizing fatty acids generate high levels of reactive oxygen species irrespective of the uncoupling protein-1 activity state. Biochim Biophys Acta 2012;1817:410-8.

62. Jeyaraju DV, Cisbani G, Pellegrini L. Calcium regulation of mitochondria motility and morphology. Biochim Biophys Acta 2009;1787:1363-73.

63. Walter L, Hajnóczky G. Mitochondria and endoplasmic reticulum: the lethal interorganelle cross-talk. J Bioenerg Biomembr 2005;37:191-206.

64. Hajnoczky G, Robb-Gaspers LD, Seitz MB, Thomas AP. Decoding of cytosolic calcium oscillations in the mitochondria. Cell 1995;82:415-24.

65. Kirichok Y, Krapivinsky G, Clapham DE. The mitochondrial calcium uniporter is a highly selective ion channel. Nature 2004;427:360-4.

66. Rottenberg H, Scarpa A. Calcium uptake and membrane potential in mitochondria. Biochemistry 1974;13:4811-7.

67. Bukowiecki LJ, Géloën A, Collet AJ. Proliferation and differentiation of brown adipocytes from interstitial cells during cold acclimation. Am J Physiol 1986;250: C880-7.

68. Matthias A, Ohlson KB, Fredriksson JM, Jacobsson A, Nedergaard J, Cannon B. Thermogenic responses in brown fat cells are fully UCP1-dependent. UCP2 or UCP3 do not substitute for UCP1 in adrenergically or fatty scid-induced thermogenesis. J Biol Chem 2000;275:25073-81.

69. Benard G, Rossignol R. Ultrastructure of the mitochondrion and its bearing on function and bioenergetics. Antioxid Redox Signal 2008;10:1313-42.

70. Casteilla L, Devin A, Salin B, Averet N, Rigoulet M. UCP1 as a water/proton co-transporter. Mitochondrion 2012;12:480-1.

71. Divakaruni AS, Brand MD. The regulation and physiology of mitochondrial proton leak. Physiology (Bethesda) 2011;26:192-205.

72. Jezek P, Jabůrek M, Garlid KD. Channel character of uncoupling protein-mediated transport. FEBS Lett 2010;584:2135-41.

73. Souza SC, Christoffolete MA, Ribeiro M0, Miyoshi H, Strissel KJ, Stancheva ZS, et al. Perilipin regulates the thermogenic actions of norepinephrine in brown adipose tissue. $\mathrm{J}$ Lipid Res 2007;48:1273-9.

74. Schrager S. Dietary calcium intake and obesity. J Am Board Fam Pract 2005;18: 205-10.

75. Marotte C, Bryk G, Gonzales Chaves MM, Lifshitz F, Pita Martín de Portela ML, Zeni SN. Low dietary calcium and obesity: a comparative study in genetically obese and normal rats during early growth. Eur J Nutr 2014; 53:769-78.

76. Davies KM, Heaney RP, Recker RR, Lappe JM, Barger-Lux MJ, Rafferty K, et al. Calcium intake and body weight. J Clin Endocrinol Metab 2000;85:4635-8.

77. Teegarden D. Calcium intake and reduction in weight or fat mass. J Nutr 2003;133: 249S-51S.

78. Zemel MB, Thompson W, Milstead A, Morris K, Campbell P. Calcium and dairy acceleration of weight and fat loss during energy restriction in obese adults. Obes Res 2004; 12:582-90.

79. Parikh SJ, Yanovski JA. Calcium intake and adiposity. Am J Clin Nutr 2003;77:281-7.

80. Zemel MB. Regulation of adiposity and obesity risk by dietary calcium: mechanisms and implications. J Am Coll Nutr 2002;21:146S-51S.

81. Zemel MB, Shi H, Greer B, Dirienzo D, Zemel PC. Regulation of adiposity by dietary calcium. FASEB J 2000;14:1132-8.

82. Sun X, Zemel MB. Calcium and dairy products inhibit weight and fat regain during ad libitum consumption following energy restriction in Ap2-agouti transgenic mice. $\mathrm{J}$ Nutr 2004;134:3054-60.

83. Sun X, Zemel MB. Calcium and 1,25-dihydroxyvitamin D3 regulation of adipokine expression. Obesity (Silver Spring) 2007; 15:340-8.

84. He YH, Song Y, Liao XL, Wang L, Li G, Alima, et al. The calcium-sensing receptor affects fat accumulation via effects on antilipolytic pathways in adipose tissue of rats fed low-calcium diets. J Nutr 2011;141:1938-46.

85. Nobre JL, Lisboa PC, Santos-Silva AP, Lima NS, Manhaes AC, Nogueira-Neto JF, et al. Calcium supplementation reverts central adiposity, leptin, and insulin resistance in adult offspring programed by neonatal nicotine exposure. J Endocrinol 2011;210: 349-59.

86. Jacobsen R, Lorenzen JK, Toubro S, KrogMikkelsen I, Astrup A. Effect of short-term high dietary calcium intake on 24-h energy expenditure, fat oxidation, and fecal fat excretion. Int J Obes (Lond) 2005;29:292-301.

87. Lorenzen JK, Nielsen S, Holst JJ, Tetens I, Rehfeld JF, Astrup A. Effect of dairy calcium or supplementary calcium intake on postprandial fat metabolism, appetite, and subsequent energy intake. Am J Clin Nutr 2007;85:678-87. 